\title{
Some experiments on the applicability of the principle of superposition to the strains of concrete subjected to changes of stress, with particular reference to prestressed concrete* $^{*}$
}

\author{
by R. D. Davies, M.A., Ph.D., A.M.I.C.E.
}

\section{Contribution by Douglas McHenry \\ (Director of Development, Portland Cement Association, Chicago, Illinois)}

In design problems involving the creep of young concrete under time-dependent stress, practical considerations seem to require that one of two basic assumptions be adopted: (1) that creep recovery upon removal of a stress increment is non-existent; (2) that change in creep resulting from removal of a stress increment is equal to change in creep resulting from the application of an equal stress increment of opposite sense. Any intermediate condition becomes too unwieldy to be useful. Many investigators have accepted assumption (1) as the simpler of the two. The second assumption involves a slightly more complex train of thought initially, but when the two concepts are reduced to mathematical expressions for use in design procedures, it turns out that assumption (2) is really the simpler. Dr Davies's analysis of prestressed beams indicates this, without emphasizing the point.

It is therefore gratifying to find that Dr Davies's carefully conducted tests have added further evidence that the principle of superposition of time-dependent stressstrain effects in concrete is a reasonable working basis. This is indeed fortunate, for if superposition were not admissible, all but the simplest of problems involving creep effects would become almost intractable.

The tests referred to by Dr Davies in the writer's 1943 publication were conducted in connexion with conditions existing in the interior of mass concrete dams, and the test specimens were therefore sealed to prevent loss of moisture. Since 1943 various investigations, several of them referred to by Dr Davies, have studied the applicability of the principle of superposition. Two other recent studies should be referred to.

Bäckström (1) in 1956 reported on tests of small beams subjected to sustained constant bending moments, using a loading and unloading sequence similar to that used by Davies. The 36 creep specimens were $2 \times 5 \times 40 \mathrm{~cm}$ and were made from cement-sand mortar. Testing was in an atmosphere of $60 \%$ relative humidity.

Ross $^{(2)}$ used compression specimens $4 \frac{5}{8}$ in. diameter by 12 in. long exposed to an atmosphere of $93 \%$ relative humidity and subjected to a variety of time-dependent loadings. The schedules included step-wise application, removal, and re-application of loads.

The Portland Cement Association laboratories recently reported $^{(3)}$ creep data for a variety of lightweight aggregate concretes with a normal-weight sand-and-gravel concrete for comparison. Specimens were $6 \times 12$ in. cylinders,

Pages 161-172 and the relative humidity of the testing room was $50 \%$. Sustained compressive stresses were $600 \mathrm{lb} / \mathrm{in}^{2}$ for cylinder strengths of 3,000 and $4,500 \mathrm{lb} / \mathrm{in}^{2}$, and $2,000 \mathrm{lb} / \mathrm{in}^{2}$ for strengths of 7,000 and $9,000 \mathrm{lb} / \mathrm{in}^{2}$. The report referred to above did not include data on creep recovery, so Table $I$ is presented here to show typical data reduced to the form $(R-Q) / P$ for comparison with Davies's Table 1 . The recovery data are of limited value for application to prestressing problems, for the initial loading age $\left(t_{0}\right)$ was 28 days and the age at unloading $\left(t_{1}\right)$ was 540 days; but they provide an addition to the gradually accumulating fund of data on creep recovery.

If $(R-Q) / P$ is greater than $1 \cdot 00$, the measured recovery is less than that predicted by the theory. The data for the sand-and-gravel concrete are in agreement with Davies's data in that all values of the ratio exceed unity. They approach closer to unity as the strength increases. The ratios for the lightweight aggregate concrete are in nearly all cases less than unity, indicating more than $100 \%$ recovery, and this was found to be generally true for the seven lightweight aggregates used in the test series. It will be noted that a large part of the deviation from unity developed in what has been designated in Table $I$ as " elastic strain", that is, at $t=0$. Davies questioned the validity of such measurements; nevertheless it is instructive to compare these values with those at later times. The comparison suggests that a part of the inaccuracy in superposition may result from differences in elastic properties of the stressed and the unstressed concretes.

\section{Contribution by Professor A. D. Ross (University of London, King's College)}

The best compliment which I can pay to the conception and planning of this research is to say that I started some experiments with the same objective in view about four years ago. A report on those tests has been published elsewhere $^{(2)}$ and I now wish merely to comment on the author's experimental technique and to offer some independent confirmation of his results, confirmation with a remarkable degree of quantitative agreement.

The testing equipment described in the paper is most elegant and I admire in particular the sand jack, the crossed knife-edges, the optical extensometers and the ingenious autocollimator. The precision of this apparatus, however, put a practical limit both on the size and on the number of the specimens and it might therefore be of interest to know that I have obtained useful creep data with the following extremely simple equipment. The cylindrical specimens, $4 \frac{5}{8}$ in. in diameter and $12 \mathrm{in.} \mathrm{long}$ are loaded " in series" with a 5 in. O.D. mild-steel tube. This tube fulfils the dual purpose of acting as part of the 
TABLE I: Measured and computed strains due to load of $1 \mathrm{lb} / \mathrm{in}^{2}$. Initial loading at 28 days; unloading at 540 days.

\begin{tabular}{|c|c|c|c|c|c|c|c|c|c|c|c|c|c|c|c|c|c|}
\hline \multirow{2}{*}{ 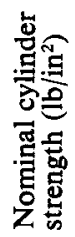 } & \multirow{2}{*}{ 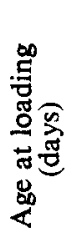 } & \multirow{2}{*}{ 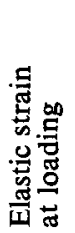 } & \multicolumn{5}{|c|}{$\begin{array}{c}\text { Elastic and creep strain } \\
\text { at age shown }\end{array}$} & \multirow{2}{*}{ 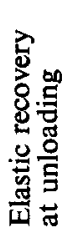 } & \multicolumn{4}{|c|}{$\begin{array}{l}\text { Elastic and creep } \\
\text { recovery }\end{array}$} & \multicolumn{5}{|c|}{$(R-Q) / P$} \\
\hline & & & |윯 & $=\sum_{\infty}^{\infty}$ & 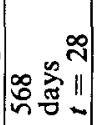 & 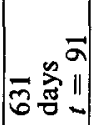 & 象急 & & $\overrightarrow{\|}$ & $\stackrel{\substack{N \\
\|}}{\|}$ & $\begin{array}{l}\bar{a} \\
11\end{array}$ & $\begin{array}{l}n \\
n \\
n\end{array}$ & $\begin{array}{l}0 \\
\| \\
-\end{array}$ & 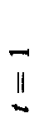 & $\stackrel{\substack{\sim \\
\|}}{\|}$ & $\bar{a}$ & $\begin{array}{c}n \\
n \\
n\end{array}$ \\
\hline
\end{tabular}

\begin{tabular}{|c|c|c|c|c|c|c|c|c|c|c|c|c|c|c|c|c|c|}
\hline \multicolumn{18}{|c|}{ LIGHTWEIGHT AGGREGATE* } \\
\hline \multirow[t]{2}{*}{3,000} & 28 & 0.715 & $1 \cdot 835$ & $1 \cdot 835$ & $1 \cdot 842$ & 1.857 & 1.900 & $0 \cdot 700$ & $0 \cdot 753$ & $0 \cdot 823$ & $0 \cdot 860$ & - & 0.94 & 0.94 & 0.95 & 0.96 & - \\
\hline & 540 & 0.661 & 0.661 & $0 \cdot 709$ & 0.785 & 0.845 & 0.979 & 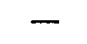 & - & 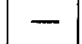 & 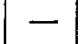 & - & & & & & \\
\hline \multirow[t]{2}{*}{4,500} & 28 & 0.645 & 1.528 & 1.528 & 1.537 & 1.553 & 1.600 & 0.593 & 0.640 & $\mid 0.681$ & 0.695 & - & 0.92 & 0.89 & 0.93 & 0.95 & - \\
\hline & 540 & 0.546 & 0.546 & 0.571 & 0.640 & 0.684 & 0.778 & . & 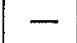 & 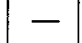 & - & - & & & & & \\
\hline \multirow[t]{2}{*}{7,000} & 28 & $0 \cdot 602$ & 0.984 & 0.984 & $0 \cdot 984$ & 0.986 & 0.993 & $0 \cdot 523$ & 0.543 & $0 \cdot 573$ & 0.593 & 0.608 & 0.82 & 0.82 & 0.87 & 0.89 & $0 \cdot 94$ \\
\hline & 540 & 0.428 & $0 \cdot 428$ & 0.448 & 0.497 & 0.529 & 0.578 & - & . & 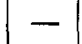 & - & - & & & & & \\
\hline \multirow[t]{2}{*}{9,000} & 28 & 0.546 & 0.905 & 0.905 & 0.905 & 0.907 & 0.913 & 0.436 & 0.458 & $0 \cdot 488$ & 0.514 & 0.545 & 0.95 & 0.95 & 0.99 & 1.00 & 1.01 \\
\hline & 540 & 0.416 & 0.416 & 0.436 & 0.485 & 0.514 & 0.558 & - & - & - & - & - & & & & & \\
\hline
\end{tabular}

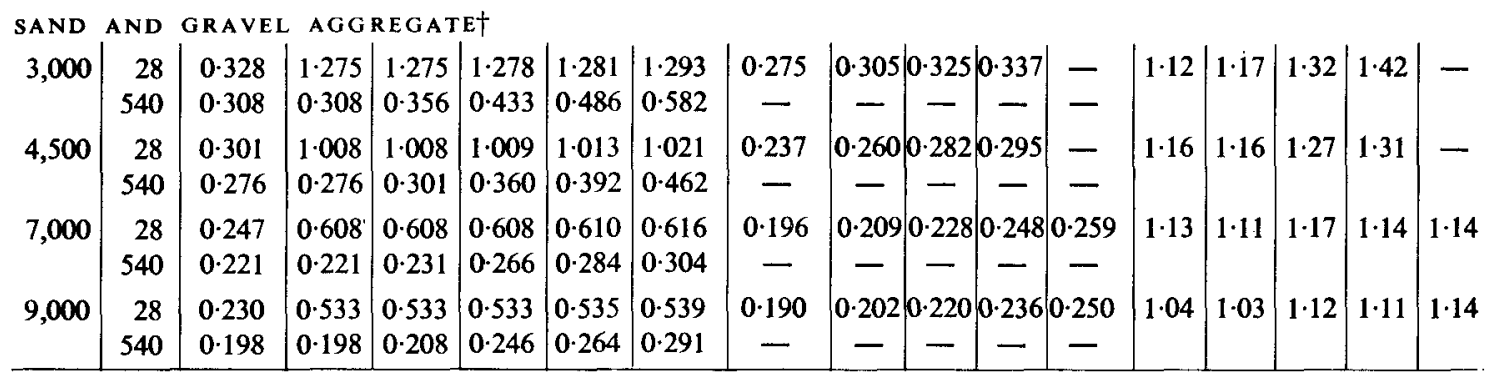

* Expanded clay, aggregate No. 4 of reference (3).

$\uparrow$ Aggregate No. 8 of reference (3).

loading " spring" and also, by measurement of its axial strain, as a dynamometer to indicate the load. Heavy end plates embrace the tube and specimen and the tension is carried by three $\frac{1}{2}$ in. diameter Macalloy bars forming the remainder of the spring.

In practice, the spring action is sufficient to ensure that only minor variations of stress take place and these are easily restored by adjustment of the tension in the tiebars. With this rig we can sustain loads of about 17 tons, which gives $2,300 \mathrm{lb} / \mathrm{in}^{2}$ in the concrete. Thirty sets of this equipment have been in use and the number can easily be increased independently of tests already in progress. A single Whittemore gauge recording strains to $10^{-5}$ has been used on all concrete specimens and on the tube dynamometers. Since each specimen and dynamometer has three gauge lengths, the precision of the mean strain measurement is somewhat better than $10^{-5}$ and, in practice, the results have been entirely satisfactory. Compared with this equipment, Dr Davies's apparatus offers (a) a much shorter loading period so that there is a clearer separation between creep and immediate strain and (b) greater precision in load application and strain measure- ment. My technique seems to provide (a) larger specimens while still operating at high stresses and (b) portability, the measurements of strain by a single instrument and the freedom to multiply tests which are independent of those already started.

Despite these interesting differences in equipment, the results obtained are comparable. For example, Figure 9 shows that the total specific strain at the age of 48 days for a concrete first loaded at 13 days (the $R$ value) is about $3.3 \times 10^{-7}$. For a comparable high-grade concrete with an aggregate/cement ratio of 4.4 and a water/cement ratio of $0 \cdot 38$, my value at 48 days for concrete loaded at 14 days was $2.8 \times 10^{-7}$. But that specific strain was obtained in a larger specimen than Dr Davies's and in a higher humidity of about $93 \%$ so that a smaller value would be expected, and the two figures are therefore in the right order of magnitude. To add some data on the principle of superposition, Table II gives the results of three tests in the form which Dr Davies uses.

In each case stress $=2,180 \mathrm{lb} / \mathrm{in}^{2}$, temperature $=17^{\circ} \mathrm{C}$ and relative humidity $=93 \%$.

The agreement with the figures quoted in Table 1 of 
TABLE II

\begin{tabular}{c|c|c|c|c|c|c|c|c}
\hline \multicolumn{2}{c|}{ Age in days at } & \multicolumn{6}{c}{$(R-Q) / P$} \\
\hline $\begin{array}{c}\text { Load- } \\
\text { ing }\end{array}$ & $\begin{array}{c}\text { Change } \begin{array}{c}\text { of } \\
\text { load }\end{array} \\
\text { End }\end{array}$ & $\begin{array}{c}\text { Ef } \\
\text { test }\end{array}$ & \multicolumn{4}{c|}{ Days after change of load } \\
\cline { 4 - 8 } 14 & 60 & 120 & 20 & 40 & 60 & 100 & 150 \\
14 & 91 & 200 & $1 \cdot 12$ & $1 \cdot 11$ & $1 \cdot 10$ & $1 \cdot 12$ & - & - \\
60 & 91 & 240 & $1 \cdot 11$ & 1.09 & 1.08 & 1.08 & 1.08 & 1.07 \\
\hline
\end{tabular}

the paper is quite remarkable.

I agree with Dr Davies that, whilst McHenry`s hypothesis is nearer to the truth than some assumptions, it is by no means strictly true and it over-estimates the recovery or under-estimates the residual strain on removal of stress. My tests show also that it under-estimates the strain when the stress is reduced either continuously or in steps. Dr Davies comments that it would be interesting to test the hypothesis under increasing increments. I have done this on a limited scale and found, as would be expected, that the hypothesis over-estimates the strain under these conditions. I believe, however, that if there are severe changes of stress, the hypothesis provides the best method of calculating strain; particularly if the stress changes sign would $I$ expect this to be so, although I have not verified it experimentally.
Reply by the author

I should like to thank Mr McHenry and Professor Ross for their very interesting contributions and for the fresh experimental evidence which they give, particularly as they have presented their results in a form directly comparable with my own. All the evidence seems to confirm that the theory of superposition is a reasonable working basis. With gravel or crushed granite aggregate, it somewhat over-estimates the recovery of creep on unloading, but with lightweight aggregate it under-estimates it. This curious fact might repay further study.

Figure 12 of the paper gave the results of the last experiment up to 28 days. The experiment continued after the paper was written, and Figure I gives the results up to 300 days. At the end of that period, the value of $(R-Q) / P$ was 1.09 .

\section{REFERENCES}

1. BÄскSTRÖM, $S$. Creep and creep recovery of cement mortar. Fifth Congress of the International Association for Bridge and Structural Engineering, Lisbon, 1956. Preliminary publication. Paper la2. pp. 77-83.

2. Ross, A. D. Creep of concrete under variable stress. Journal of the American Concrete Institute. Vol. 29, No. 9. March 1958. pp. 739-758.

3. SHIDELER, J. J. Lightweight-aggregate concrete for structural use. Journal of the American Concrete Institute. Vol. 29, No. 4. October 1957. pp. 299-328.

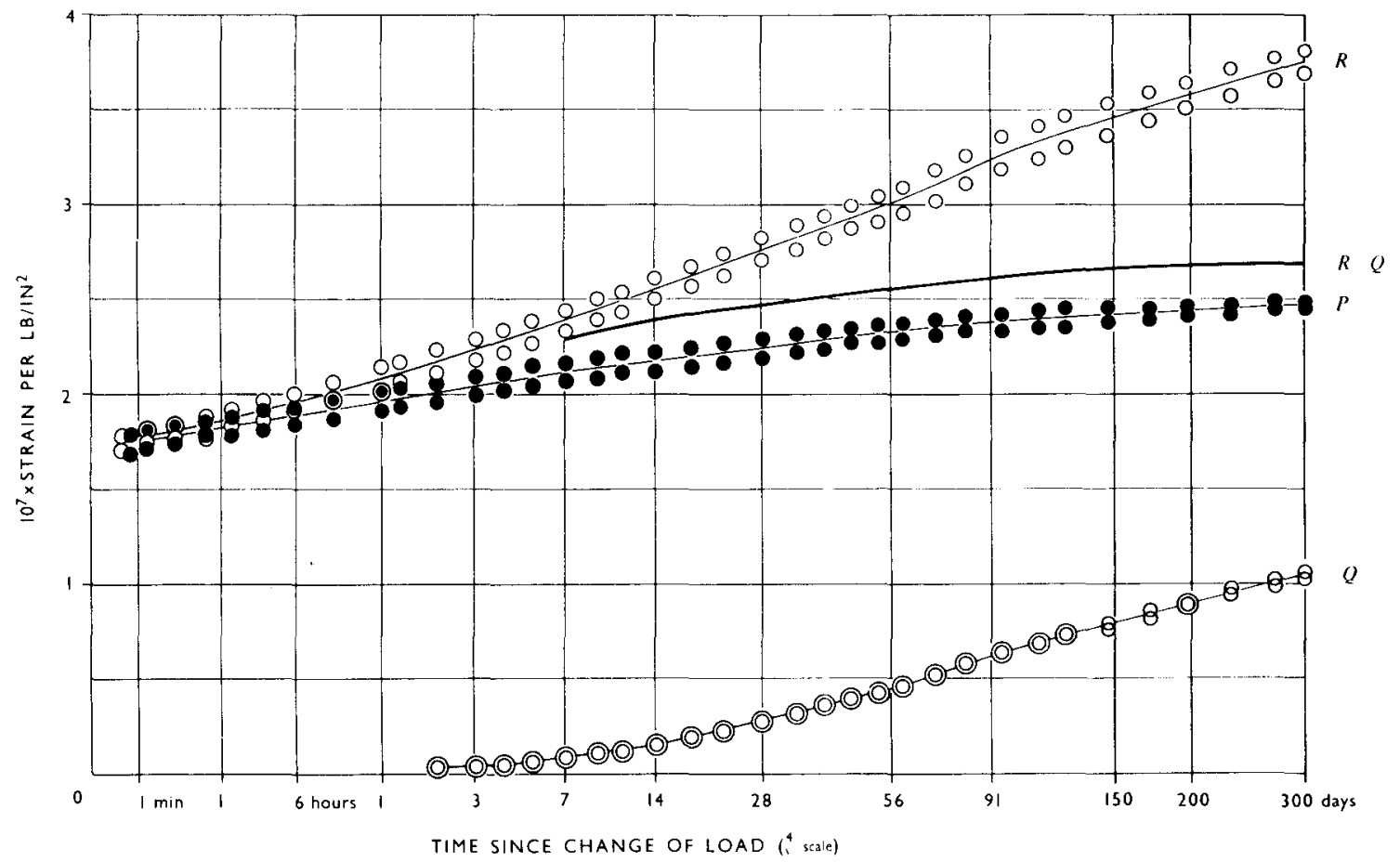

Figure 1: Results of the last experiment up to 300 days. 